\title{
Competências e habilidades para empregabilidade dos egressos de administração: a experiência de uma universidade gaúcha
}

Este estudo tem como premissa a relevância da formação de bacharéis do curso de Administração com as competências requeridas pelas organizações e as habilidades para atuar em diferentes modelos e níveis organizacionais. Possui como objetivo apresentar as percepções dos egressos de uma universidade comunitária localizada na região Noroeste do Rio Grande do Sul e dos empregadores desses egressos a partir das oito competências citadas nas diretrizes curriculares do MEC. Estas oito competências são tipificadas por Fonseca et al. (2007) como transversais e técnicas, as competências transversais são àquelas que têm foco no desenvolvimento individual e social, e as competências técnicas enfatizam o desenvolvimento profissional. Caracteriza-se como uma pesquisa aplicada exploratória, descritiva e qualitativa. Do ponto de vista dos procedimentos técnicos é uma pesquisa de cunho bibliográfico, documental e estudo de caso, que culminou com a análise de conteúdo. Os resultados evidenciam que, na percepção das amostras, o egresso tem dificuldade em relacionar a teoria com a prática e carecem de experiência gerencial, entretanto, é apontada como fatores positivos: a aprendizagem nas diferentes áreas organizacionais, a participação em eventos, à realização de estágios e a formação em uma universidade bem-conceituada pelo MEC. Desta forma, o desafio da empregabilidade dos egressos está em integrar o conhecimento teórico de sala de aula, a habilidade técnica e um comportamento adequado ao profissional da Administração que as organizações requerem.

Palavras-chave: Curso de Administração; Empregabilidade; Competências.

\section{Skills and skills for employability of administration grades: the experience of a Brazilian university}

\begin{abstract}
This study has as premise the relevance of the bachelors training of the Administration course with the competencies required by the organizations and the abilities to act in different models and organizational levels. It aims to present the perceptions of the graduates of a community university located in the Northwest region of Rio Grande do Sul and the employers of these graduates from the eight competencies cited in the curricular guidelines of the MEC. These eight competencies are typified by Fonseca et al. (2007) as transversal and technical, transversal competences are those that focus on individual and social development, and technical skills emphasize professional development. It is characterized as an applied, exploratory, descriptive and qualitative research. From the point of view of the technical procedures is a research of bibliographical, documentary and case study, culminating with the content analysis. The results show that, in the perception of the samples, the egress has difficulty in relating the theory to the practice and lack management experience, however, it is pointed out as positive factors: learning in the different organizational areas, participation in events, internships and training at a university well-regarded by the MEC. In this way, the challenge of the graduates' employability lies in integrating the theoretical knowledge of the classroom, the technical skill and behavior appropriate to the professional of the Administration that the organizations require.
\end{abstract}

Keywords: Administration Course; Employability; Skills.

Topic: Teoria Geral da Administração

Reviewed anonymously in the process of blind peer.
Received: 10/01/2019

Approved: 20/04/2019

\section{Eliana Ribas Maciel}

Universidade Regional do Noroeste do Estado do Rio Grande do Sul, Brasil http://lattes.cnpq.br/7109940275419147

eliana.maciel@unijui.edu.br

\section{Ana Claudia Bueno Grando}

Universidade Regional do Noroeste do Estado do Rio Grande do Sul, Brasil aninha_bueno10@hotmail.com

\section{Jessica Casali Turcato (ic)}

Universidade Regional do Noroeste do Estado do Rio Grande do Sul, Brasil http://lattes.cnpq.br/9932389241976026

http://orcid.org/0000-0003-1982-6868

jehturcato@hotmail.com

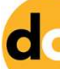

DOI: 10.6008/CBPC2179-684X.2018.001.0001
Marinês Ribas

Universidade Regional do Noroeste do Estado do Rio Grande do Sul, Brasil http://lattes.cnpq.br/0500128558346335

marines.ribas@yahoo.com.br

Martinho Luís Kelm (iD

Universidade Regional do Noroeste do Estado do Rio Grande do Sul, Brasil http://lattes.cnpq.br/2798758797454828

http://orcid.org/0000-0002-4004-1574

martinho@unijui.edu.br

Referencing this:

MACIEL, E. R.; GRANDO, A. C. B.; TURCATO, J. C.; RIBAS, M.; KELM, M. L.. Competências e habilidades para empregabilidade dos egressos de administração: a experiência de uma universidade gaúcha. Revista Brasileira de Administração Científica, v.9, n.1, p.1-13, 2018. DOI: http://doi.org/10.6008/CBPC2179-684X.2018.001.0001 


\section{INTRODUÇÃO}

O dinamismo do contexto organizacional exige atenção às mudanças e inovações para responder adequadamente às demandas, sem perder competitividade. Neste ambiente, o mercado de trabalho requer profissionais qualificados, empreendedores e com visão abrangente, que consigam contribuir efetivamente para o melhor alinhamento dos clientes, pessoas, processos e estratégias organizacionais.

Nesta ótica, o profissional de Administração precisa ter competências para gerenciar as organizações, delineando estratégias com foco em resultados positivos. Estas competências implicam em buscar continuamente conhecimento, desenvolver habilidades técnicas e ter comportamento proativo para identificar as oportunidades e as ameaças, de forma propositiva, e não se tornar um profissional mediano.

O ambiente organizacional tem exigido do Administrador competências teóricas, técnicas e comportamentais, para diagnosticar problemas e oportunidades, realizar projetos, tomar decisões, bem como desenvolver relações interpessoais e interorganizacionais, dentre outras funções. Neste entendimento, as possibilidades de inserção no mercado de trabalho estão relacionadas às competências e habilidades que os profissionais desenvolvem ao longo da sua trajetória de formação e de atuação nas organizações.

Neste cenário, o papel do curso de Administração é de estimular e promover o desenvolvimento das competências a fim de inserir os egressos no ambiente organizacional, preparando-os para atuar em diferentes modelos e setores organizacionais, compreender processos operacionais e assumir cargos de nível tático ou estratégico, contudo, a formação acadêmica precisa estar alinhada com as expectativas deste ambiente.

O projeto pedagógico do curso de Administração, objeto deste estudo, observa a Resolução no 4/2005 do Conselho Nacional de Educação, do Ministério da Educação (MEC), que instituiu as Diretrizes Curriculares Nacionais dos Cursos de Administração. Estas diretrizes apresentam as competências e habilidades em um conjunto de saberes e conhecimentos de várias instâncias, de formação geral e profissional, da experiência de trabalho e do envolvimento social, desta forma expressa que todo e qualquer curso de Administração deve possibilitar a formação profissional.

Diante destes pressupostos, a questão central do estudo é: 'a partir das percepções dos egressos do curso de Administração e das organizações que os empregam, quais os desafios, oportunidades e fragilidades destes egressos para a inserção no mercado de trabalho?'. Objetiva ainda relatar as percepções dos egressos e empregadores no tocante as dificuldades, oportunidades e desafios da empregabilidade destes bacharéis.

O artigo está dividido em cinco capítulos, neste primeiro momento são apresentados os aspectos introdutórios e a proposta do estudo. No segundo, são abordados os fundamentos teóricos da ciência da Administração, organizações, competências do Administrador e a empregabilidade. No terceiro capítulo estão descritos os aspectos metodológicos. Na sequência com o quarto capítulo é apresentado os resultados do estudo e, por fim, no último e quinto capítulo, são traçadas as considerações finais, concluindo com as referências do artigo. 


\section{REVISÃO TÉORICA}

\section{Ciência da administração}

A Administração nas suas diferentes abordagens pode ser analisada como uma ciência que por meio de processos de decisão conduz a organização para alcançar seus objetivos e metas, em um contexto social. No decorrer da história, a Administração, enquanto ciência, continuamente esteve presente no cotidiano das pessoas e das empresas. Chiavenato (2001) explica que apesar dos progressos no conhecimento humano, a ciência da Administração despontou no século XX, após a Revolução Industrial, ele define que a “Administração é uma ciência que estuda as organizações com finalidade descritiva e explicativa para compreender sua natureza e funcionamento, sua evolução e crescimento e seu comportamento".

Corrobora Lacombe (2009), ao mencionar que a Administração é como uma arte diagnosticar, elaborar planos, dimensionar objetivos, rumos e recursos, dirigir pessoas e monitorar o alcance de resultados econômicos, sociais e ambientais nas organizações. Destarte, administrar significa desenvolver um processo administrativo que inicia com um diagnóstico do contexto organizacional para a formulação de planos, organiza processos, aloca recursos, dirige pessoas, e monitora o impacto deste ciclo sobre o desempenho das organizações. Nesta ótica, Chiavenato (2001) qualifica a Administração como o processo de planejar, organizar, dirigir e controlar o uso dos recursos organizacionais para alcançar os objetivos de maneira eficiente e eficaz.

A Administração enquanto um processo procura assegurar a eficácia e eficiência das organizações. Nesta ótica, Maximiano (2012) relata "Administração é o processo de tomar decisões sobre objetivos e utilização de recursos". No entendimento de Silva (2008), a Administração é um conjunto de atividades dirigidas a utilização eficiente e eficaz dos recursos, no sentido de alcançar um ou mais objetivos ou metas da organização. A busca pela eficiência nos processos de decisão e no uso dos recursos e nas organizações tem sido uma constante exigência do ambiente competitivo em que estas atuam.

Na mesma linha, a Administração estabelece como utilizar os recursos organizacionais para alcançar objetivos e atingir desempenho positivo. Segundo Maximiano (2012) "embora o processo administrativo seja importante em qualquer contexto de utilização de recursos, a razão principal para estuda-lo é o seu impacto sobre o desempenho das organizações". Nesta abordagem, Chiavenato (2001) contribui:

\footnotetext{
A Administração tornou-se importante na condução da sociedade moderna. Ela não é um fim em si mesma, mas um meio de fazer com que as coisas sejam realizadas da melhor forma, com o menor custo e com a maior eficiência e eficácia. Fazer cada vez mais com cada vez menos. Nesse sentido, a Administração agrega valor e riqueza as organizações e as pessoas.
}

No entendimento de Mintzberg et al. (2001) para as estratégias organizacionais serem eficientes, os recursos precisam ser alocados em padrões que proporcionem recursos suficientes para cada investida, independente da relação custo/benefício. Neste contexto, a formação do profissional em Administração pressupõe entender esta como uma ciência, com um processo e como uma área profissional regulamentada. A profissão de Administrador no Brasil foi oficialmente criada em 09 de setembro de 1965, pela Lei no 4.769/65 e Regulamentada e aprovada pelo Decreto no 61.934/67. A partir desta lei foi instituída a profissão 
de Administrador, definindo campos de trabalho, competências requeridas, enfim definindo direitos e obrigações destes que se habilitariam ao exercício desta profissão, diplomados em educação superior.

Neste cenário fica evidenciado que a Administração enquanto uma ciência exige que o profissional da Administração desempenhe os processos organizacionais de forma científica, seguindo uma metodologia específica e não apenas pelo senso comum, mas ainda requer uma estratégia de construção do capital intelectual e da base de dados constituindo um sistema de apoio às decisões.

\section{Organizações}

A organização enquanto um sistema dinâmico e complexo tem recebido diferentes conceituações. A propósito, Chiavenato (2001) define que:

A organização significa o arranjo e disposição dos recursos organizacionais para alcançar objetivos estratégicos. Esse arranjo se manifesta na divisão do trabalho em unidades organizacionais, como divisões ou departamentos e cargos, a definição de linhas formais de autoridade e a adoção de mecanismos para coordenar as diversas tarefas organizacionais.

Outrossim, uma organização é uma combinação de esforços individuais que tem por finalidade realizar propósitos coletivos. Além de pessoas, as organizações utilizam outros recursos, como máquinas, equipamentos, dinheiro, tempo, espaço e conhecimento (MAXIMIANO, 2012). O mesmo autor relata que por meio de uma organização, é possível perseguir e alcançar objetivos que seriam inatingíveis para uma pessoa. Considerando que cada organização tem uma missão específica e que as pessoas que a compõem advém de diferentes áreas do conhecimento, torna-se relevante que a missão seja absolutamente clara e alinhada, de modo a evitar que cada um defina os 'resultados' em termos de sua própria especialidade e sobreponha os seus valores aos da organização (DRUCKER, 1998).

As operações da organização ocorrem em um contexto ambiental, dinâmico e complexo, impactado por contínuas mudanças intrínsecas e extrínsecas. Segundo Chiavenato (2010), o sucesso de cada organização depende da sua capacidade de adequar-se continuamente as transformações que ocorre ao seu redor respondendo as necessidades dos clientes, avanços tecnológicos, tendências econômicas, mudanças sociais e culturais, novos regulamentos legais, dentre outros fatores. A este respeito, Robbins (2001) indica que as organizações estão se tornando mais flexíveis e suscetíveis a seus ambientes.

Na visão de Chiavenato (2010), toda mudança em uma organização representa alguma modificação nas atitudes cotidianas, nas relações de trabalho, nas responsabilidades, nos hábitos e comportamentos das pessoas que são os membros da organização. Para Hampton (1992), as mudanças estão ocorrendo nos métodos e equipamentos de trabalho, nas normas, na estrutura, nas práticas de controle, nos padrões de comunicação entre as pessoas, no projeto do trabalho, nas técnicas do planejamento e em outros aspectos das empresas.

No entendimento de que existe um relacionamento recíproco entre as organizações e seus ambientes, Hall (2004) explica que as organizações acarretam impactos aos indivíduos e à sociedade. Assim, considerando que as organizações estão inseridas em um ambiente dinâmico, faz-se necessário que o 
profissional da Administração tenha as competências e habilidades para atuar neste mercado de trabalho específico.

\section{Competências do administrador e a empregabilidade}

A empregabilidade implica no desenvolvimento de competências específicas da atuação profissional do Administrador. O estudo de Fleury et al. (2004) conceitua competências citando Parry (1996) como sendo o "conjunto de conhecimentos, habilidades, atitudes que afetam a maior parte do trabalho de uma pessoa, e que se relacionam com o desempenho no trabalho; a competência pode ser mensurada, quando comparada com padrões estabelecidos e desenvolvida por meio do treinamento".

Conforme Fleury et al. (2004) é importante desenvolver nas pessoas competências que não apenas agregam valor a organização, mas também ao indivíduo. Segundo Chiavenato (2010), as habilidades são a capacidade de transformação do conhecimento em ação e que resultarão no desempenho desejado. As competências técnicas do administrador incluem técnicas de gestão administrativa, de estruturação organizacional, como organogramas, fluxogramas, layouts, definição de diretrizes, normas e procedimentos organizacionais, técnicas de análise, avaliação (diagnóstico) e estruturação organizacional, de administração de pessoal, abrangendo o domínio de sua legislação específica e de administração de materiais.

Nesta ótica, Andrade (2007) explicita as funções básicas do Administrador como sendo: planejar a implantações das decisões tomadas hoje para um futuro próximo; organizar a distribuição do poder das tarefas, das responsabilidades e da prestação de contas; dirigir as pessoas a partir dos estilos de liderança e de direção; e controlar os recursos organizacionais.

Nesta linha, o perfil generalista com visão especialista é essencial ao administrador que queira atuar como consultor (OLIVEIRA, 2004). Neste campo de atuação, o profissional da Administração precisa ter uma visão abrangente do ambiente e uma estratégia adequada de inserção, uma vez que suas proposições interdependem e interagem com outros processos da organização. Esta atitude empreendedora faz com o que o profissional assuma responsabilidade direta de transformar uma ideia em projeto lucrativo (ANGELO, 2003).

Para este estudo, cabe referenciar as competências e habilidades do Administrador, apresentadas pelo Ministério da Educação, no artigo 4ํㅡ, da resolução CNE/CES no 4/2005 do Conselho Nacional de Educação, conforme as Diretrizes Curriculares Nacionais do Curso de Graduação em Administração Bacharelado, apresentadas no Quadro 01. Estas oito competências são tipificadas por Fonseca et al. (2007) como sendo transversais e técnicas. Considera competências transversais aquelas que têm foco no desenvolvimento individual e social, quais sejam da primeira a quinta competência. As demais são as competências técnicas com foco no desenvolvimento profissional.

A partir desta referência, o PPC do curso de Administração da universidade estudada estabelece que o perfil profissional do bacharel contemple as competências teórico-conceituais inerentes aos conteúdos de formação profissionalizante, de formação básica, de estudos quantitativos e suas tecnologias e de formação complementar e de formação humanista, constituindo assim uma sólida formação teórico-conceitual-crítico- 
reflexiva, em uma visão inter/intra/multidisciplinar, necessária para subsidiar a tomada de decisão em um ambiente criativo e inovador, bem como as competências técnicas, comportamentais, ético-profissionais, orientadas ao empreendedorismo.

Quadro 01: Competências e habilidades do Administrador.

\begin{tabular}{|c|}
\hline $\begin{array}{l}\text { I- reconhecer e definir problemas, equacionar soluções, pensar estrategicamente, introduzir modificações nos processos, atuar } \\
\text { preventivamente, transferir e generalizar conhecimentos e exercer, em diferentes graus de complexidade, o processo da tomada } \\
\text { de decisão; }\end{array}$ \\
\hline $\begin{array}{l}\text { II - desenvolver expressão e comunicação compatíveis com o exercício profissional, inclusive nos processos de negociação e nas } \\
\text { comunicações interpessoais ou intergrupais; }\end{array}$ \\
\hline $\begin{array}{l}\text { III - refletir e atuar criticamente sobre a esfera da produção, compreendendo sua posição e função na estrutura produtiva sob seu } \\
\text { controle e gerenciamento; }\end{array}$ \\
\hline $\begin{array}{l}\text { IV - desenvolver raciocínio lógico, crítico e analítico para operar com valores e formulações matemáticas presentes nas relações } \\
\text { formais e causais entre fenômenos produtivos, administrativos e de controle, bem assim expressando-se de modo crítico e criativo } \\
\text { diante dos diferentes contextos organizacionais e sociais; }\end{array}$ \\
\hline $\begin{array}{l}\text { V - ter iniciativa, criatividade, determinação, vontade política e administrativa, vontade de aprender, abertura às mudanças e } \\
\text { consciência da qualidade e das implicações éticas do seu exercício profissional; }\end{array}$ \\
\hline $\begin{array}{l}\text { VI - desenvolver capacidade de transferir conhecimentos da vida e da experiência cotidianas para o ambiente de trabalho e do } \\
\text { seu campo de atuação profissional, em diferentes modelos organizacionais, revelando-se profissional adaptável; }\end{array}$ \\
\hline VII - desenvolver capacidade para elaborar, implementar e consolidar projetos em organizações; \\
\hline VIII - desenvolver capacidade para realizar consultoria em gestão e administração, pareceres e per \\
\hline
\end{tabular}
Fonte: Resolução CNE/CES no 4/2005 (BRASIL, 2005).

O ambiente profissional do Administrador exige o aperfeiçoamento constante das competências e habilidades para a sua inserção, manutenção e ascensão no mercado de trabalho. Na concepção de Dutra (2008) "o mercado de trabalho é constituído por relações dinâmicas e complexas entre pessoas que oferecem sua capacidade de trabalho e organizações que oferecem oportunidades de trabalho".

Wright (2010) relata que diante das tendências e desafios no mercado de trabalho, tem ganhado crescente importância o conceito de empregabilidade, além de destacar que a Organização Internacional do Trabalho (OIT, 2001) define empregabilidade como uma capacidade do indivíduo para assegurar e manter um trabalho digno, para progredir dentro da empresa e entre os empregos, e para fazer face à evolução das tecnologias e condições do mercado de trabalho. Nesta temática, vale notar as contribuições de Oliveira et al. (2009), que a empregabilidade de um indivíduo depende de sua capacidade de desenvolver e manter um conjunto de conhecimentos, habilidades e atitudes que sejam atraentes aos potenciais empregadores.

Previdelli et al. (2000) acrescentam que o mercado requer do Administrador uma multiqualificação que desenvolva o poder de tomar decisões e de auto organizar-se para a realidade das constantes mudanças e imprevisibilidades que uma ampla base educacional possa proporciona. A propósito, a configuração do mercado exige um conjunto generalista de competências e habilidades para o exercício da Administração. Neste aspecto, reforça o importante papel que desempenham os cursos superiores de Administração na elaboração projetos pedagógicos alinhados as expectativas do mercado de trabalho.

\section{METODOLOGIA}

A metodologia, segundo Minayo (1994), não só contempla a fase exploratória de campo, mas também, a definição de instrumentos e procedimentos para análise dos dados. A pesquisa do ponto de vista de sua natureza se classifica como uma pesquisa aplicada que se refere a discussão de problemas, 
empregando um referencial teórico. Do ponto de vista de seus objetivos, este estudo é classificado como uma pesquisa exploratória (VERGARA, 2004), pois buscou um maior conhecimento do tema estudado e descritiva (ROESCH, 2006) porque delineou as características dos egressos do curso e as percepções dos empregadores.

Quanto à forma de abordagem do problema é uma pesquisa qualitativa, em que foram analisadas questões dissertativas do questionário e descritiva, pois os pesquisadores analisaram seus dados indutivamente (BEUREN et al., 2008). Do ponto de vista dos métodos de procedimentos técnicos (GIL, 2010), é uma pesquisa bibliográfica, documental que envolveu levantamento de dados a partir do PPC do Curso de Administração e um estudo de caso singular.

Os sujeitos da pesquisa concentram-se em dois universos distintos: os egressos do curso de administração de uma Universidade Comunitária localizada na região Noroeste do estado do Rio Grande do Sul e os gestores das organizações empregadoras destes egressos. Do universo dos egressos formados no curso de Administração de uma Universidade nos anos de 2014, 2015 e 1o semestre de 2016, foi extraída a amostra e aplicado o instrumento de pesquisa no formato de questionário, a parti delas, foram identificadas as organizações empregadoras. Os integrantes da amostra foram determinados de modo não probabilístico e de forma intencional, em função da acessibilidade e conveniência (MINAYO, 1994).

A coleta de dados realizou-se por meio do preenchimento de questionários enviados por meio eletrônico às amostras da pesquisa. Como técnica de mensuração utilizou-se a Escala de Likert, e adotou-se quatro escalas sendo: discordo totalmente, discordo, concordo e concordo totalmente, na intenção de evitar a neutralidade, de não concordar e nem discordar. A análise dos dados ocorreu por meio da análise de conteúdo para posterior interpretação (TRIVIÑOS, 1987; MINAYO, 1994). Os dados foram categorizados e ordenados, relacionadas suas semelhanças e identificadas as tendências ou padrões proeminentes.

A pesquisa conta com uma amostra de 93 questionários respondidos por egressos, composta por 10\% com idade inferior a 23 anos, $62 \%$ até 24 anos e $28 \%$ acima de 31 anos. Da amostra, 17\% ocupam cargo de Administradores em suas empresas, $17 \%$ ocupam o cargo de assistente administrativo, $20 \%$ ocupam cargo de gerência e os demais aguardam inserção no mercado de trabalho. $O$ grupo dos gestores das organizações empregadoras está composto por oito respondentes.

\section{RESULTADOS E DISCUSSÃO}

Os resultados do estudo aplicado apresentam um comparativo das percepções da amostra com as competências e habilidades do egresso que constam no PPC do curso de Administração em uma universidade, bem como, a análise das percepções dos egressos quanto a sua inserção no mercado de trabalho e dos gestores das organizações empregadoras. $\mathrm{O}$ quadro 2 apresenta um comparativo dos resultados da pesquisa a partir das oito competências do egresso do curso de Administração.

Conforme o quadro comparativo, $66,18 \%$ dos egressos concordam que desenvolvem a competência le $63 \%$ dos empregadores também concordam, contudo, $17 \%$ dos empregadores discordam nesta afirmação, principalmente no quesito identificar corretamente os problemas e pensar estrategicamente. Para Mintzberg 
et al. (2001) as decisões estratégicas determinam a direção e a eficiência do empreendimento, bem como as mudanças que podem ocorrer.

Quadro 2: Comparativo das percepções da amostra.

\begin{tabular}{|l|l|l|l|l|}
\hline COMPETÊNCIAS DO ADMINISTRADOR & $\begin{array}{l}\text { DISCORDO } \\
\text { TOTALMENTE }\end{array}$ & DISCORDO & CONCORDO & $\begin{array}{l}\text { CONCORDO } \\
\text { TOTALMENTE }\end{array}$ \\
\hline
\end{tabular}

Competência I: reconhecer e definir problemas, equacionar soluções, pensar estrategicamente, introduzir modificações no processo produtivo, atuar preventivamente, transferir e generalizar conhecimentos e exercer, em diferentes graus de complexidade, o processo da tomada de decisão.

\begin{tabular}{|l|l|l|l|l}
\hline Egressos & $1,02 \%$ & $4,62 \%$ & $66,18 \%$ & $28,18 \%$ \\
\hline Empregadores & $0 \%$ & $17 \%$ & $63 \%$ & $20 \%$ \\
\hline
\end{tabular}

Competência II: desenvolver expressão e comunicação compatíveis com o exercício profissional, inclusive nos processos de negociação e nas comunicações interpessoais ou intergrupais.

\begin{tabular}{|l|l|l|l|l|}
\hline Egressos & $0,88 \%$ & $1,73 \%$ & $64,06 \%$ & $33,33 \%$ \\
\hline Empregadores & $0 \%$ & $20,84 \%$ & $58,33 \%$ & $20,83 \%$ \\
\hline
\end{tabular}

Competência III: refletir e atuar criticamente sobre a esfera da produção, compreendendo sua posição e função na estrutura produtiva sob seu controle e gerenciamento.

\begin{tabular}{|l|l|l|l|l|}
\hline Egressos & $1,3 \%$ & $17,95 \%$ & $61,5 \%$ & $19,25 \%$ \\
\hline Empregadores & $0 \%$ & $25 \%$ & $50 \%$ & $25 \%$ \\
\hline
\end{tabular}

Competência IV: desenvolver raciocínio lógico, crítico e analítico para operar com valores e formulações matemáticas presentes nas relações formais e causais entre fenômenos produtivos, administrativos e de controle, bem assim expressando-se de modo crítico e criativo diante dos diferentes contextos organizacionais e sociais.

\begin{tabular}{|l|l|l|l|l|}
\hline Egressos & $0 \%$ & $9,4 \%$ & $58,1 \%$ & $32,5 \%$ \\
\hline Empregadores & $0 \%$ & $33,33 \%$ & $54,17 \%$ & $12,5 \%$ \\
\hline
\end{tabular}

Competência V: ter iniciativa, criatividade, determinação, vontade política e administrativa, vontade de aprender, abertura às mudanças e consciência da qualidade e das implicações éticas do seu exercício profissional.

\begin{tabular}{|l|l|l|l|l|}
\hline Egressos & $0 \%$ & $3,08 \%$ & $29,22 \%$ & $67,7 \%$ \\
\hline Empregadores & $0 \%$ & $2,86 \%$ & $66,78 \%$ & $30,36 \%$
\end{tabular}

Competência VI: desenvolver capacidade de transferir conhecimentos da vida e da experiência cotidianas para o ambiente de trabalho e do seu campo de atuação profissional, em diferentes modelos organizacionais, revelando-se profissional adaptável.

\begin{tabular}{|l|l|l|l|l|}
\hline Egressos & $0 \%$ & $10,26 \%$ & $68,41 \%$ & $21,33 \%$ \\
\hline Empregadores & $0 \%$ & $25 \%$ & $62,5 \%$ & $12,5 \%$ \\
\hline Competência VII: desenvolver capacidade para elaborar, implementar e consolidar projetos em organizaçães. \\
\hline Egressos & $0 \%$ & $16,23 \%$ & $62,4 \%$ & $21,37 \%$ \\
\hline Empregadores & $0 \%$ & $41,66 \%$ & $45,84 \%$ & $12,5 \%$ \\
\hline $\begin{array}{l}\text { Competência VIII: desenvolver capacidade para realizar consultoria em gestão e administração, pareceres e perícias } \\
\text { administrativas, gerenciais, organizacionais, estratégicos e operacionais. }\end{array}$ & $2,56 \%$ & $41,03 \%$ & $44,43 \%$ & $11,98 \%$ \\
\hline Egressos & $0 \%$ & $45,83 \%$ & $41,8 \%$ & $12,37 \%$ \\
\hline Empregadores & &
\end{tabular}

No que se refere à competência II, 64,06\% dos egressos concordam que desenvolvem comunicação compatível com o exercício profissional, sendo que dos empregadores, 58,33\% concordam que os egressos possuem esta competência, contudo $20,84 \%$ dos empregadores discordaram, sendo este um item de maior variação com os egressos. Conforme Maximiano (2002), as habilidades dividem-se em conceituais e interpessoais, neste sentido faz-se necessário que o Administrador tenha habilidades para interagir com grupos de pessoas.

No tocante à competência III, $61,5 \%$ dos egressos concordam que sabem atuar na esfera da produção e $50 \%$ dos gestores também concordam. A outra metade dos gestores divide a opinião entre discordo e concordo totalmente. Para Chiavenato (2001) e Andrade (2007) a administração é o processo de planejar, organizar, dirigir e controlar, para isto, o Administrador precisa compreender sua posição e função na estrutura produtiva sob seu gerenciamento.

No comparativo da competência IV, 58,1\% dos egressos concordam estarem aptos a desenvolverem raciocínio lógico, crítico e analítico para operar com valores matemáticos e 54,17\% dos empregadores tem a 
mesma percepção. Por sua vez, 32,5\% dos egressos concordam totalmente que tenham esta competência, contudo 33,33\% dos empregadores discordam desta posição. Em relação à competência $V$ verifica-se uma inversão nos posicionamentos da amostra quanto às escalas concordam e concordam totalmente. Observase que $67,7 \%$ dos egressos concordam totalmente que tenham iniciativa, criatividade e estão abertos a mudanças, contudo apenas $30,36 \%$ dos empregadores compartilham desta opinião. Por sua vez, 66,78\% dos empregadores e $29,22 \%$ dos egressos estão situados na escala concordo.

Com relação à competência VI, cabe destacar que $25 \%$ dos empregadores discordam que os egressos se revelam como profissionais adaptáveis aos contextos organizacionais. Nesta competência, conforme mostra o quadro comparativo, $68,4 \%$ dos egressos concordam ter capacidade de transferir conhecimentos e experiências vivenciadas para o seu ambiente de trabalho e do seu campo de atuação profissional, pois o Administrador deve saber aplicar os conhecimentos e experiências.

Quanto à competência VII, 41,66\% dos empregadores discordam de que os egressos sabem elaborar, implementar e consolidar projetos enquanto que $16,23 \%$ dos egressos tem a mesma percepção. Segundo Maximiano (2012) administrar é elaborar planos de negócio e pôr em ação. Observa-se um consenso na competência VIII, em que 41,03\% dos egressos e 45,83\% dos empregadores entendem que os egressos não estão aptos a realizar consultorias e perícias e emitir pareceres na área administrativa. Para Oliveira (2004), o consultor precisa atuar como um agente de desenvolvimento organizacional, capaz de influenciar nos comportamentos, atitudes e processos que promovam mudanças estruturadas no intuito de posicionar a empresa diante das mudanças no ambiente interno e externo da organização.

A análise das percepções dos egressos evidencia que a maior concordância, na média de 97,39\%, ocorre na competência II, no que se refere ao desenvolvimento da expressão e comunicação compatíveis com o exercício profissional. E a maior discordância, na média de 43,59\%, é verificada na competência VIII no tocante a capacidade de realizar consultorias, perícias e pareceres administrativos. Corroboram os empregadores ao ratificar esta como maior discordância na média $45,83 \%$.

Na percepção dos empregadores, a maior concordância, em média de 97,14\%, ocorre na competência $V$ no que se refere às atitudes proativas dos egressos. Sendo está a competência com maior concordância entre os egressos e os empregadores, com uma média de 97,03\%. Ainda, nesta análise da média das percepções, a competência VIII apresenta-se como sendo a mais frágil, em que na média de $44,71 \%$ dos egressos e empregadores entendem que os egressos não estão aptos a realizar consultorias, perícias e pareceres administrativos quando do seu ingresso no mercado de trabalho.

Dentre os relatos das dificuldades para a empregabilidade dos egressos, tem destaque o insipiente conhecimento prático, a falta de experiência e a associação da teoria da sala de aula com a prática do dia a dia, tornando-se assim difícil a aplicação na esfera real das organizações. Os egressos reiteram que o curso deveria ter disciplina prática para realizar perícias administrativas e consultoria, desta forma, cometendo erros e acertos haveria melhor aprendizagem.

Outro obstáculo citado se refere às dificuldades para conseguir uma oportunidade, em uma organização de pequeno porte, que acredite no potencial do Administrador e que este pode fazer a diferença 
na sua empresa. Cabe também citar a percepção de que são limitadas as possibilidades de emprego com remuneração adequada à formação em uma região menos desenvolvida economicamente, reiteram que as vagas, em sua maioria, são para cargos de nível operacional e na área de vendas.

No relato dos gestores é possível perceber essas dificuldades dos egressos, principalmente com a falta habilidade prática, pois ao serem questionados se a evolução do contratado atendeu as expectativas do empregador, as opiniões ficaram divididas, para alguns, os egressos atenderam às expectativas fazendo a inter-relação entre o teórico e a complexidade do trabalho, para outros, o processo acontece gradativamente. No relato de um gestor, os egressos têm potencial para contribuir mais com a empresa, principalmente no que se refere a pensar novas estratégias e avaliar melhor as variáveis para tomada de decisão.

Outra concepção é de que ao ingressar nos processos administrativos de uma empresa pequena eles vêm com a referência pré-concebida de uma empresa grande. Mesmo, com esforço para a adaptação, carecem de envolvimento para compreender a ligação entre as atividades cotidianas. Também, indicam que o profissional sai preparado para ser empregado e não empreendedor, reconhecem que o curso não capacita o profissional a ter todas as competências, mas auxilia nos conhecimentos para desenvolvê-las e afirmam que é a atitude, a dedicação e o objetivo de vida do profissional que vai definir o seu sucesso.

Como oportunidades os egressos reconhecem o conhecimento alcançado na universidade, a importância da teoria conciliada às práticas, a visão sobre a empregabilidade no campo de atuação do administrador. Destacam também as oportunidades de estágios e a Empresa Júnior oferecida pelo curso, a participação em eventos e viagens de estudo, o contato presencial com os professores. Os gestores visualizam como oportunidades para os egressos do curso de Administração os conhecimentos e a formação em uma universidade bem-conceituada no MEC. Relatam que os egressos têm potencial de crescimento nas organizações ao agregar valor e qualidade nos processos das empresas, o mercado de trabalho para o Administrador está em expansão.

Como principais desafios para a inserção dos egressos é mencionado o elevado número de administradores com formação superior disponíveis no mercado de trabalho, o reduzido número de empresas de grande porte e o elevado número de empresas familiares na região. Outro desafio é contribuir efetivamente para valorização da profissão e a formação de líderes nas organizações. Como proposição, os egressos sugerem que o curso ofereça estágio curricular nas diferentes áreas de gestão, que possibilitem ao aluno vivenciar os processos decisórios de uma organização, também, sugerem aumentar o nível de exigência nas avaliações das disciplinas, de modo a melhor preparar o aluno para o nível de exigência empresarial.

Os empregadores alertam que os profissionais têm dificuldade em identificar soluções e tomar decisões assertivas com foco no melhor resultado. Nesta linha, relatam que os egressos hesitam em antever os impactos da sua decisão, e isto, é falta de visão do todo, também, mencionam que a visão sistêmica facilita a análise de uma empresa de menor porte, contudo os cursos, na maioria das vezes, preparam para enxergar uma área da empresa e não o todo negócio. 
Conforme relatos dos empregadores, os egressos precisam expressar melhor a vontade de crescer e perceber que a atividade desenvolvida não é um fim, mas a construção de uma caminhada que poderá levalos para novas oportunidades e que para propor mudanças ou melhorias, o profissional de administração precisa conhecer em profundidade a realidade da empresa.

Os principais desafios, citados pelos gestores para a inserção dos egressos do curso de Administração nas empresas é o aprimoramento de suas competências comportamentais como diferencial competitivo no mundo do trabalho, profissionais com capacidade para tomar decisões e prover melhorias nos processos administrativos. Reiteram que os egressos precisam planejar com profissionalismo uma pós-graduação, pois é um diferencial para conquistar as melhores vagas ou empreender em um negócio próprio, mas corroboram com a necessidade de atualização profissional para intervir com qualidade ao assumir cargos de gerência, promovendo os resultados esperados pela empresa.

\section{CONCLUSÕES}

Os resultados deste estudo indicam que as percepções dos egressos, de uma forma geral, é uma visão positiva de si mesmo e consideram-se capazes de desenvolver o conjunto das competências propostas pelas diretrizes curriculares. Reconhecem sua fragilidade para fazer consultoria, perícia e pareceres administrativos, como também, relacionar a teoria das salas de aula com a prática cotidiana nas organizações, assim, a falta de experiência na área de formação e a incipiente trajetória profissional contraposta ao alto nível de exigência do mercado de trabalho limitam a empregabilidade do egresso.

Outrossim, a ocupação de cargos administrativos por profissionais de outras áreas tem dificultado a entrada dos egressos em administração no mercado de trabalho específico de sua formação, por sua vez, a análise das percepções dos empregadores demonstra que, de uma forma mais crítica também concordam que os egressos são capazes de desenvolver as competências. Contudo, enfatizam que os bacharéis têm carências para inserção imediata no mercado de trabalho, faltando experiência e práticas para atuar como gestores nas áreas funcionais de uma organização.

$\mathrm{Na}$ análise das dificuldades para a empregabilidade, tanto egressos como os gestores revelaram os percalços para correlacionar as teorias, conceitos e modelos aprendidos em sala de aula com a prática cotidiana em empresas de pequeno a grande porte, mas, se para os egressos é intrincado implementar ideias em uma empresa, para os gestores é difícil encontrar profissionais com capacidade de tomar decisões assertivas, promover melhorias, agregar valor e atuar em diferentes funções na organização.

Além do que, apontam que o curso direciona o aprendizado para empresas de grande porte e os alunos tem a expectativa de trabalhar nestas organizações. Contudo, o contexto regional indica que os alunos precisam estar preparados para a inserção nas empresas de pequeno porte, saber resolver problemas de menor complexidade, se adaptar a organizações que não tem departamentos estruturados e sistemas informatizados.

Contrapondo as dificuldades de empregabilidade, os egressos valorizam a formação acadêmica, a participação em eventos da área, o intercambio em viagens de estudos, a realização de estágios e a atuação 
na Empresa Júnior, dentre outras oportunidades de interação com os diferentes ambientes organizacionais, também reconhecem que o diferencial de um Administrador está na sua capacidade de tomar decisões e gerenciar situações de forma dinâmica, proativa e estratégica.

Tanto os egressos como os gestores destacam como ponto positivo que o curso possibilita atuar em diferentes áreas no mercado de trabalho, além do que incentiva o empreendedorismo e o intraempreendedorismo. Diante destes resultados e do dinamismo dos contextos organizacionais torna-se desafiador, tanto para o discente quanto para o docente e, também para o empregador, encontrar estratégias para superar as dificuldades de empregabilidade dos egressos dos cursos superiores em Administração.

Assim, muito se tem discutido a respeito da empregabilidade dos egressos dos cursos superiores, mas o desafio está em compreender o que as organizações requerem, integrando o currículo do curso, os fundamentos teóricos, as metodologias ativas que simulam realidades organizacionais e permitem uma melhor aprendizagem por meio de problematizações, bem como as competências e habilidades técnicas e comportamentais para a formação do Administrador.

\section{REFERÊNCIAS}

ANDRADE, R. O. B.; AMBONI, N.. Teoria Geral da

Administração: das origens as perspectivas

contemporâneas. São Paulo: M. Books do Brasil, 2007.

ANGELO, E. B.. Empreendedor corporativo: a nova postura de quem faz a diferença. Rio de Janeiro: Campus, 2003.

BEUREN, I. M.; RAUPP, F. M.. Metodologia da Pesquisa Aplicável às Ciências Sociais. São Paulo: Atlas, 2008.

BRASIL. Diretrizes Curriculares Nacionais do Curso de Graduação em Administração e bacharelado. Resolução CNE/CES no 4, de 13 de julho de 2005. Brasília, 2005

CHIAVENATO, I.. Administração nos novos tempos. 2 ed. Rio de Janeiro: Elsevier, 2010.

CHIAVENATO, I.. Teoria Geral da Administração. 6 ed. Rio de Janeiro: Campus, 2001.

DUTRA, J. S.. Gestão de Pessoas: Modelo, processos, tendências e perspectivas. 1 ed. São Paulo: Atlas, 2008

DRUCKER, P.. Profissão de Administrador. São Paulo: Pioneira, 1998.

FLEURY, A.; FLEURY, M. T. L.. Estratégias empresariais e formação de competências: Um quebra-cabeça caleidoscópio da indústria brasileira. 3 ed. São Paulo: Atlas S.A. 2004.

FONSECA, J. S. P.; MAGINA, S. M. P.; BRAGA, E.; OLIVEIRA, I. M. M.. A Influência da Formação em Administração nas Habilidades e Competências do Administrador (Futuro e Atual). In: ENCONTRO NACIONAL DOS PROGRAMAS DE PÓSGRADUAÇÃO EM ADMINISTRAÇÃO, 31. Anais. Rio de Janeiro: ENANPAD, 2007
GIL, A. C.. Como elaborar projetos de pesquisa. 5 ed. São Paulo: Atlas, 2010

HALL, R. H.. Organizações. Estruturas, processos e resultados. 8ed. São Paulo: Prentice Haal, 2004.

HAMPTON, D. R.. Administração contemporânea. 3 ed. São Paulo: Makron Books, 1992.

LACOMBE, F.. Teoria Geral da Administração. São Paulo: Saraiva, 2009.

MAXIMIANO, A. C. A.. Teoria geral da administração: da revolução urbana à revolução digital. 7 ed. São Paulo: Atlas, 2012.

MAXIMIANO, A. C. A.. Teoria Geral da Administração: Da escola cientifica a competitividade na economia globalizada. 2 Ed. São Paulo: Atlas, 2002.

MINAYO, M. C. S.. Pesquisa Social: Teoria, método e criatividade. 22 ed. Rio de Janeiro: Vozes, 1994.

MINTZBERG, H.; QUINN, J. B.. O processo de estratégia. Porto Alegre: Bookman, 2001.

OLIVEIRA, D. P. R.. Manual de consultoria empresarial: conceitos, metodologia, práticas. São Paulo: Atlas, 2004.

OLIVEIRA, L. B.; WETZEL, U.. Rumo ao Mercado de Trabalho: Percepções e Estratégias de Jovens Estudantes de Administração. 2009.

OIT. Organização Internacional do Trabalho. Desemprego juvenil no Brasil: em busca de opções à luz de algumas experiências internacionais. 2001. 
PREVIDELLI, J. J.; CÔRTES, R. S.. Globalização e mercado de trabalho do administrador. São Paulo: ANGRAD, 2000.

ROBBINS, S. P.. Administração: mudanças e perspectivas. 2a triagem. São Paulo: Saraiva, 2001

ROESCH, S. M. A.. Projetos de estágio e de pesquisa em administração: Guia para estágios, trabalhos de conclusão, dissertações e estudos de caso. 3 ed. São Paulo: Atlas, 2006.

SILVA, R. O.. Teorias da Administração. São Paulo: Pearson Prentice Hall, 2008
TRIVIÑOS, A. N. S.. Introdução à pesquisa em Ciências Sociais. São Paulo: Atlas, 1987.

VERGARA, S. C.. Projetos e Relatórios de Pesquisa em Administração. 5 ed. São Paulo: Atlas, 2004.

WRIGHT, J. T. C.. O mercado de trabalho no futuro: uma discussão sobre profissões inovadoras, empreendedorismo e tendências para 2020. Revista de Administração e Inovação, São Paulo, v.7, n.3, p.174-197, 2010.

A CBPC - Companhia Brasileira de Produção Científica (CNPJ: 11.221.422/0001-03) detém os direitos materiais desta publicação. Os direitos referem-se à publicação do trabalho em qualquer parte do mundo, incluindo os direitos às renovações, expansões e disseminações da contribuição, bem como outros direitos subsidiários. Todos os trabalhos publicados eletronicamente poderão posteriormente ser publicados em coletâneas impressas sob coordenação da Sustenere Publishing, da Companhia Brasileira de Produção Científica e seus parceiros autorizados. Os (as) autores (as) preservam os direitos autorais, mas não têm permissão para a publicação da contribuição em outro meio, impresso ou digital, em português ou em tradução. 